\title{
A PRESCRIÇÃ̃O NO CÓDIGO CIVIL BRASILEIRO (OU O JOGO DOS SETE ERROS)
}

\author{
THE STATUTE OF LIMITATIONS IN THE BRAZILIAN CIVIL CODE \\ (OR THE GAME OFSEVEN ERRORS)
}

\section{Rodrigo Xavier Leonardo*}

RESUMO: O Código Civil de 2002 apresentou inovações substanciais em tema de prescrição. No presente artigo, propõe-se uma análise crítica das opções legislativas adotadas pelo direito brasileiro. A partir de uma análise de direito comparado, que auxilia a compreender as influências recebidas de outros sistemas em tema de prescrição, procura-se apontar insuficiências da codificação e possíveis caminhos interpretativos para sua superação. A conclusão é por sete conjuntos argumentativos críticos que demandam esforço hermenêutico, também apresentado ao leitor, para um tratamento adequado da matéria.

PALAVRAS-CHAVE: Prescrição. Direito comparado. Insuficiências. Perspectivas hermenêuticas.

ABSTRACT: The Civil Code of 2002 made substantial innovations in the subject of the statute of limitations. In this paper, we propose a critical analysis of legislative options adopted by Brazilian Law. From a comparative law analysis, which helps to understand the influences received from other systems on the theme of limitation, we try to point out possible weaknesses in the coding and interpretive paths to overcoming it. The conclusion is for seven argumentative and critic sets that demand hermeneutic effort, also presented to the reader to a proper treatment of the subject.

KEYWORDS: Comparative Law. Shortcomings. Hermeneutical perspectives.

* Professor adjunto de Direito Civil nos cursos de graduação e pós-graduação da Universidade Federal do Paraná (UFPR). Mestre e Doutor em Direito Civil pela Universidade de São Paulo (USP). Vice-Coordenador do Programa de Pós-Graduação em Direito da Universidade Federal do Paraná (UFPR). Advogado. 


\section{INTRODUÇÃO}

A prescrição se insere dentre os assuntos que, não obstante todo o estudo e a experiência acumulados por séculos, ainda se verificam espaços para dúvidas e incertezas.

Isso se faz ainda mais presente diante duma nova codificação que alterou substancialmente as linhas mestras deste instituto, tal como se sucedeu no direito brasileiro mais recente.

No presente escrito se propõe uma análise crítica da prescrição no Código Civil de 2002, em busca da demonstração das vantagens e vicissitudes da legislação codificada, tomando por fontes de reflexão os aportes da doutrina, da jurisprudência e, em especial, do direito comparado ${ }^{1}$.

\section{A PRESCRIÇÃO: LINEAMENTOS GERAIS}

O termo prescrição usualmente é utilizado tanto para traduzir uma espécie de fato jurídico como para explicar uma particular eficácia jurídica. Essa indistinção entre os significados reconhecidos ao mesmo significante pode ser considerada a primeira dificuldade na abordagem do instituto.

Como uma particular espécie de fato jurídico², a prescrição se forma a partir dum determinado suporte fático composto por eventos e ações humanas. $\mathrm{O}$ suporte fático da prescrição é complexo, envolvendo eventos (o transcurso do tempo) e ações humana (a inação do titular de uma determinada situação jurídica ativa).

A tríade de elementos necessários à prescrição (transcurso do tempo, inação e titularidade de situação jurídica ativa) se justifica por um olhar atento ao instituto sob investigação.

Sob os mais diferentes enfoques, e em termos similares em direito comparado, no conjunto plural de elementos para formação do fato jurídico prescrição é incontroverso que o transcurso do tempo deve estar presente.

1 Em virtude dos limites inerentes a um artigo, decidiu-se abordar o direito comparado a partir do Direito Civil dalguns países Europeus (Itália, França, Alemanha, Portugal Espanha) e da região da Catalúnia, ao lado dos Códigos de outros países da América Latina (Argentina, Uruguai e Bolívia). A respeito do direito comparado como disciplina que orienta uma reflexão crítica do direito positivo, cf. FRADERA, Véra Maria Jacob. Reflexões sobre a contribuição do direito comparado para a elaboração do direito comunitário. Belo Horizonte: Del Rey, 2010, em especial p.158 e seguintes.

2 Adotamos a orientação teórica de que o fato jurídico é o resultado da incidência da norma jurídica sobre determinado suporte fático. A incidência, por sua vez, se dá quando na realidade cotidiana ocorrem os fatos (suporte fático concreto) em conformidade suficiente ao que é abstratamente descrito em norma jurídica (suporte fático abstrato). Sobre o assunto, cf. PONTES DE MIRANDA. Tratado de Direito Privado. t.I. 3.ed. Rio de Janeiro: Borsoi, 1970; Mais recentemente, com grande avanço didático e inovações, o tema foi explorado de maneira singular por BERNARDES DE MELLO, Marcos. Teoria do fato jurídico: plano da existência.15.ed. São Paulo: Saraiva, 2008. Ambos os autores servirão como marco teórico para a exposição realizada. 
O fluir do tempo, entremeado por um termo inicial e um termo final fixado pela Lei, no entanto, não é suficiente para configurar a prescrição. Além da fluência do tempo, mostra-se necessária a ocorrência de uma inação do titular de uma situação jurídica ativa (direito/pretensão/ação) ${ }^{3}$.

Segundo fórmula em geral adotada nos diversos ordenamentos jurídicos, o lapso prescricional pode ser impedido (evitando o termo inicial para o cômputo do tempo), pode ser suspenso (detendo o progresso da contagem do tempo) e pode ser interrompido (rompendo o cálculo do tempo para que o mesmo seja reiniciado).

A possibilidade do impedimento, suspensão ou interrupção do prazo prescricional decorre, justamente, do segundo elemento que se deve verificar para a composição do fato jurídico prescrição: a inércia do sujeito.

Nem toda inércia, nem toda a omissão do titular duma situação jurídica ativa será considerada adequada para a configuração da prescrição. Em certos casos, o elemento inércia do titular se dá em circunstâncias nas quais o direito positivo reconhece não ser conveniente configurar a prescrição, razão pela qual seria injusto imputar os efeitos a ela pertinentes. Justamente por isso, a norma jurídica possibilita o impedimento, a suspensão e a interrupção do lapso prescricional ${ }^{4}$.

Tome-se como exemplo a disciplina encontrada no Código Civil Brasileiro, nos artigos 197 a 202. Quando a legislação impede que o termo inicial da prescrição inicie, entre os cônjuges, na constância do casamento (art. 197, I, CCB) ou quando suspende o curso da prescrição contra um militar em serviço das Forças Armadas em tempos de guerra (art. 198, III, CCB), a objetiva inação do titular de uma situação jurídica ativa é desqualificada para o fim da composição da prescrição.

Em tais circunstâncias concretas não seria razoável exigir qualquer atuação por parte daqueles sujeitos e, justamente por isso, a legislação cria válvulas para impedir, suspender ou interromper o lapso temporal prescricional.

Dispositivos similares a esses podem ser encontrados em todas as legislações estrangeiras aqui analisadas. Em termos razoavelmente gerais, pode-se dizer que a composição da prescrição não se dá apenas e tão somente pela fluência do tempo. Mostra-se necessária a ocorrência de uma inação do titular em circunstâncias que o direito positivo considere adequado avaliar esta inércia como justificadora da composição da prescrição e da subsequente eficácia prescricional ${ }^{5}$.

3 Deixemos, por ora, a discussão sobre o objeto da prescrição. O tema será abordado adiante.

4 Compreendendo que a avaliação subjetiva da conduta integra a noção de inércia que é própria e indispensável à prescrição, CABRAL DE MONCADA, Luís. Lições de Direito Civil. 4.ed. Coimbra: Almedina, 1995, p.740; ANDRADE, Manuel A. D. Teoria geral da relação jurídica. t.II. Coimbra: Almedina, 1988, p.446; MOTA PINTO, Carlos Alberto. Teoria geral do Direito Civil. 3.ed. Coimbra: Almedina, 1993, p.376).

5 Registre-se que, segundo a compreensão predominante, a referida adequação das circunstâncias diria respeito, apenas e tão somente, à política legislativa. Isto porque, conforme adverte Messineo, "la legge non richiede che l'inerzia del titolare sia volontaria, ossia effetto di negligenza; essa si riporta al fatto, schiettamente oggettivo, del mancato esercizio"(MESSINEO, Francesco. Manuale di Diritto Civile e Commerciale. Milano: Giuffrè, 1957, p.178) 
Se em relação aos elementos do transcurso do tempo e da inação do sujeito se verifica uma compreensão praticamente pacífica a respeito do tema, o esclarecimento da situação jurídica que se titulariza na prescrição é um campo absolutamente controverso.

Nele se comunica a abordagem da prescrição como particular fato jurídico e como espécie de eficácia jurídica, tal como antes alertado. Isto porque a situação jurídica titularizada pelo sujeito que se queda inerte por um determinado lapso temporal, a um só tempo, servirá para definir o terceiro elemento para a composição do fato jurídico e indicará o objeto a ser atingido pelo efeito da prescrição.

Num esforço de comparação entre os ordenamentos jurídicos antes assinalados, as soluções encontradas para esta questão podem ser agrupadas em quatro modelos.

No modelo francês, a prescrição é tratada como um meio de se adquirir e ou de se liberar em virtude de um lapso temporal ${ }^{6}$. Reconhece-se, portanto, a possibilidade de uma eficácia constitutiva e de uma eficácia extintiva a partir do fato jurídico prescrição. A despeito de o texto legislativo não ser claro quanto ao objeto que se extingue ou se constitui, mediante uma interpretação sistemática, pode-se dizer que a prescrição medeia o surgimento ou a liberação de um direito subjetivo.

$\mathrm{O}$ direito subjetivo, portanto, seria o terceiro elemento para a configuração do fato jurídico e, ao mesmo tempo, seria o alvo da eficácia da prescrição (bifurcada em aquisitiva e extintiva).

Similar ao tratamento encontrado no Código Civil Francês são as soluções verificadas no Código Civil Espanhol ${ }^{7}$, no Código Civil Argentino ${ }^{8}$ e no Código Civil Uruguaio $^{9}$, ainda que com algumas ressalvas ${ }^{10}$.

Para além das divergências pontuais - e sem pretender minorar a importância de cada uma delas -, verifica-se como traço comum a circunstância de o fato jurídico

6 “Art. 2.219. La prescription est un moyen d'acquérir ou de se libérer par un certain laps de temps, et sous les conditions déterminées para la loi”

7 “Art. 1.930. Por la prescripción se adquieren, de la manera y con las condiciones determinadas en la ley, el dominio y demás derecho reales. También se extinguen del proprio modo por la prescripción los derechos y las acciones, de cualquier clase que sean"

8 “Art. 3.947. Los derechos reales y personales se adquieren y se pierden por la prescripción. La prescripción es un medio de adquirir un derecho, o de libertarse de una obligación por el transcurso del tempo".

9 “Art. 1188. La prescripción es un modo de adquirir o de extinguir los derechos ajenos. En el primer caso se adquiere el derecho por la posesión continuada por el tiempo y con los requisitos que la ley señala. En el segundo, se pierde la acción por el no uso de ella en el tiempo señalado por la ley. Para esta clase de prescripción, la ley no exige título ni buena fe".

${ }^{10}$ Advirta-se, no entanto, a ressalva de que, no Código Civil Espanhol, expressamente, reserva-se a prescrição aquisitiva para os direitos reais e a prescrição extintiva para todos os demais direitos e ações; no Código Civil Argentino, verifica-se a particularidade de que, expressamente, tanto a prescrição extintiva como a aquisitiva atingiriam os direitos reais e pessoais e, por fim, no Código Civil Uruguaio, restringe-se a prescrição aquisitiva aos direitos decorrentes da posse ou a perda de "ações" pela inércia de seu titular. 
prescrição albergar tanto uma eficácia aquisitiva como uma eficácia extintiva. Não se percebe muita clareza sobre o objeto da prescrição no texto da legislação comparada analisada, mencionando-se por vezes a extinção das figuras direito e ação.

O Código Civil Italiano nos conduz a um segundo modelo. Nele, a prescrição teria eficácia extintiva, capaz de atingir qualquer direito subjetivo, com exceção para os direitos indisponíveis e para outros direitos indicados pela $\mathrm{Lei}^{11}$. $\mathrm{O}$ mesmo enunciado legal pode ser encontrado no Código Civil Boliviano ${ }^{12}$

O terceiro modelo a ser destacado provém do Código Civil Alemão. No BGB, a prescrição é definida no parágrafo 194 como a extinção da pretensão (Anspruch), conceituada como o "direito de se exigir de outrem uma ação ou omissão"13. A influência do BGB pode ser verificada no recente Código Civil da Catalúnia ${ }^{14}$.

Por fim, pode-se encontrar noutras legislações algumas opções não alinhadas aos modelos anteriores. Por razões didáticas, vamos considerá-las como um quarto modelo. O Código Civil português é paradigmático neste sentido, ao evitar definir a prescrição, limitando-se a discipliná-la nos artigos 300 a 327. Ainda que o artigo 306, 2 deste Código mencione de passagem "a prescrição de direitos"15, não se pode afirmar que o legislador daquele país assimilou a orientação teórica que defende a extinção de direitos subjetivos pela prescrição ${ }^{16}$.

11 “Art. 2934. Ogni diritto si estingue per prescrizione, quando il titolare non lo esercita per il tempo determinato dalla legge. Non sono soggetti alla prescrizione i diritti indisponibili e gli altri diritti indicati dalla legge".

12 “Art. 1492. I. Los derechos se extinguen por la prescripción cuando su titular no los ejerce durante el tiempo que la ley establece. II. Se exceptúan los derechos indisponibiles y los que la ley señala en casos particulares".

13 “§ 194. Das Recht, von einem Anderen ein Thun oder ein Unterlassen zu verlangen (Anspruch), unterliegt der Verjährung". No volume que compõe a tradução espanhola do Tratado de Direito Civil de EnneccerusKipp-Wolf pode-se ler a seguinte tradução: “§ 194. El derecho de exigir de otro una acción o una omisión (pretensión) se extingue por prescripción” (INFANTE, Carlos Melon. Código Civil Aleman. Barcelona: Bosch, 1994, p.38)

14 “Art. 121-1. La prescripció extingeix les pretensions relatives a drets disponibles, tant si s'exerceixen en forma d'acció com si s'exerceixen en forma d'excepció. S'entén com a pretensió el dret a reclamar d'altri una acció o una omissió".

15 “(...) 2 - A prescrição de direitos sujeitos a condição suspensiva ou termo inicial só começa depois de a condição se verificar ou o termo se vencer"

${ }^{16}$ Não obstante o texto do Código Civil Português não se posicionar no sentido de que a prescrição atingiria o próprio direito subjetivo, esta concepção é forte na doutrina. Neste sentido, cf. CABRAL DE MONCADA, Luís. Lições de Direito Civil. 4.ed. Coimbra: Almedina, 1995, p.729; MOTA PINTO, Carlos Alberto. Teoria geral do Direito Civil. 3.ed. Coimbra: Almedina, 1993, p.373; PRATA, Ana. Dicionário jurídico. t.I. 5.ed. Coimbra: Almedina, 2008, p.1091; ANDRADE, Manuel A. D. Teoria geral da relação jurídica. t.II. Coimbra: Almedina, 1988, p.446 (com a observação de que, para este autor, uma vez extinto o direito subjetivo em decorrência da prescrição, surgiria uma obrigação natural). Em sentido contrário, Pedro Paes de Vasconcelos defende que o efeito jurídico da prescrição seria um "enfraquecimento" do direito subjetivo consistente em que a pessoa vinculada pode recusar o cumprimento ou a conduta a que esteja adstrita (VASCONCELOS, Pedro Pais de. Teoria geral do direito civil. 3.ed. Coimbra: Almedina, 2005, p.756). 
Diante destes modelos cabe questionar qual o que melhor auxilia a compreensão do Código Civil Brasileiro de 2002.

\section{A PRESCRIÇÃO NO DIREITO GIVIL BRASILEIRO}

O Código Civil de 2002 procura alinhar o Direito Civil brasileiro, em tema de prescrição, ao modelo alemão. Isso se percebe claramente pelo texto do artigo 189, que abre o capítulo a respeito do assunto.

Pode-se ler nesse dispositivo que "violado o direito, nasce para o titular a pretensão, a qual se extingue, pela prescrição, nos prazos a que aludem os arts. 205 e 206".

Não bastasse a menção textual de que a eficácia da prescrição corresponderia à extinção de uma pretensão (e não de um direito subjetivo), a aproximação teórica com o Código Civil Alemão é também confirmada por José Carlos Moreira Alves, jurista responsável pela redação da Parte Geral no anteprojeto do Código Civil de 2002 (MOREIRA ALVES, 2003, p. 157).

O Código Civil Brasileiro, no entanto, está muito longe de ser uma mera reprodução do modelo alemão, a começar pelo fato de que em seu texto não se encontra uma definição do que vem a ser a pretensão que seria supostamente extinta pela prescrição.

Enquanto o BGB definiu expressamente a pretensão como o "direito de exigir de outrem uma ação ou omissão", o Código Civil Brasileiro limita-se a dispor que a pretensão nasceria da violação de um direito, sem estipular o que se deve compreender pelo termo pretensão.

Ademais, para além da semelhança na definição legislativa, especialmente no que diz respeito ao objeto de aplicação da prescrição, se verificam grandes diferenças entre os códigos nos temas do impedimento, suspensão e interrupção do prazo prescricional.

Tomando em conta o desenvolvimento da matéria entre os autores nacionais, pode-se interpretar o termo pretensão como o poder de exigir uma prestação de outrem, num sentido similar à definição encontrada no Código Civil Alemão.

A pretensão seria algo a mais do que o direito subjetivo, que é categoria eficacial de cunho estático. Quem tem em mãos um direito subjetivo é titular de uma situação jurídica ativa que é estática por estar destituída, ainda que em princípio, de um poder de exigibilidade, de uma possibilidade de atuação sobre a esfera jurídica alheia para se exigir um cumprimento.

Justamente para diferenciar o momento estático do momento tensionado, parece adequado adotar, para a segunda situação, quando já há pré-tensão, o termo pretensão.

$\mathrm{O}$ credor de uma determinada quantia entregue em mútuo com termo final para devolução daqui a dois meses já é credor, hoje. É titular de um direito subjetivo. O crédito integra o seu patrimônio. Não obstante tudo isso, este mesmo credor nada pode exigir do devedor antes do advento do termo final para a devolução da importância mutuada. 
Quem é titular de uma pretensão tem em mãos, repita-se, algo a mais. Titulariza uma situação jurídica dinâmica: detém o poder de exigir uma prestação, positiva ou negativa, de alguém. Em nosso exemplo anterior, com o advento do termo ad quem para a devolução da importância emprestada, o credor passaria a deter não apenas o direito subjetivo, mas também a pretensão.

Nem todos os direitos subjetivos ensejariam pretensões e, na medida em que esta figura seria o objeto da prescrição, nem todos os direitos subjetivos estariam sujeitos à prescrição. A pretensão só surgiria nas situações em que o titular da posição subjetiva ativa na relação jurídica fosse munido do poder de exigir uma prestação daquele que se encontra na posição subjetiva passiva correspectiva.

A diferenciação entre o direito subjetivo e a pretensão, no entanto, não é suficiente para a interpretação da prescrição no Código Civil Brasileiro. Mostra-se necessário o prévio conhecimento de outras categorias eficaciais que hipoteticamente podem compor o objeto da relação jurídica.

A precisão teórica na diferenciação das categorias eficaciais foi alcançada em direito nacional a partir da obra de Pontes de Miranda, podendo ser representada por quatro binômios de eficácias de conteúdo contraposto:

ao direito subjetivo $\leftrightarrow$ corresponde o dever;

à pretensão $\leftrightarrow$ corresponde a obrigação;

à ação em sentido material $\leftrightarrow$ corresponde a situação de acionado;

à exceção de direito material $\leftrightarrow$ corresponde a situação de exceptuado;

ao poder formativo (constitutivo, modificativo ou extintivo) $\leftrightarrow$ corresponde a situação de sujeição.

A original contribuição de Pontes de Miranda em esclarecer essas diversas categorias eficaciais, seguido do singular trabalho interpretativo e explicativo dalguns juristas nacionais ${ }^{17}$, é um pressuposto essencial para a compreensão da prescrição.

${ }^{17}$ A respeito do assunto, cf. BERNARDES DE MELLO, Marcos. Teoria do fato jurídico: plano da existência. 15.ed. São Paulo: Saraiva, 2008, em especial p.182; TOMASETTI, Alcides (et alli). Comentários à Lei de locações de imóveis urbanos. São Paulo: Saraiva, 1991, p.5. Em data mais recente, o assunto é enfrentado nestes termos por NOGUEIRA, Pedro Henrique Pedrosa. Teoria da ação de direito material. Salvador: Juspodivm, 2008, p.112 e EHRHARDT JR, Marcos. Direito Civil: LICC e Parte Geral. v.I. Salvador: JusPodivm, 2009, p.463-465. Interessante leitura a respeito do tema, com enfoque no direito anglo-americano, pode ser encontrada em HOHFELD, Wesley Newcomb. Fundamental legal conceptions as applied in judicial reasoning. New Haven: Yale University Press, 1920, p.36. No Brasil, a partir da construção de HOHFELD, destaca-se o trabalho de FERREIRA, Daniel Brantes. Teoria dos direitos subjetivos. Rio de Janeiro: GZ, 2009. 
Apenas quando se compreende a existência destas categorias eficaciais e a diferença entre cada uma delas, torna-se possível compreender o que a prescrição atinge e o que a prescrição não atinge em direito brasileiro.

Ao escolher como objeto da eficácia extintiva a pretens $\tilde{a}^{18}{ }^{18}$, ou seja, o poder de exigir uma prestação, se torna claro que a prescrição é um fenômeno próprio ao campo do direito material. As eventuais projeções ao direito de ação (em sentido processual) só se justificam de modo reflexo, tal como se dá com o corpo em relação ao espelho ${ }^{19}$.

Porque a pretensão e a ação em sentido material são encobertas pela prescrição, o seu titular não pode se servir dos remédios processuais, da ação em sentido processual. A consequência processual de não poder se servir da "ação", no entanto, não tem o condão de explicar o instituto. Trata-se de um resultado decorrente de uma prévia eficácia que se sucedeu no direito material.

A diferenciação entre as categorias eficaciais e a fixação do objeto da prescrição sobre a pretensão tornou possível superar a confusão, reinante em direito nacional, de que a prescrição extinguiria a ação, normalmente compreendida apenas no sentido de remédio processual, de ação processual.

Em conclusão parcial, pode-se sustentar que o Código Civil Brasileiro busca se alinhar ao modelo teórico alemão. Esta aproximação, no entanto, é parcial e acaba por ensejar algumas inconsistências adiante expostas.

${ }^{18}$ Pontes de Miranda e Marcos Bernardes de Mello mencionam que a prescrição atingiria a pretensão e a ação em sentido material. Conforme explica Marcos Bernardes de Mello, a coextensão entre pretensão e ação em sentido material não é necessária, ainda que em regra ela ocorra. Justamente por isso, segundo este autor, em situações excepcionais, seria possível à prescrição atingir a ação em sentido material em situações em que não se verifique uma prévia pretensão, uma vez que a coextensão entre a pretensão e a ação seria um princípio não essencial (Sobre o assunto, cf. BERNARDES DE MELLO, Marcos. Teoria do fato jurídico: plano da eficácia. 3.ed. São Paulo: Saraiva, 2007, p.183).

19 O Supremo Tribunal Federal já decidiu que "o prazo estatuído em lei como termo para a extinção do direito, seja ele considerado de decadência ou de prescrição, é de direito material (dos que se integram no ramo do direito em que nasce a pretensão); de direito processual é a norma sobre a forma de ação" (RTJ 61/93). Noutra oportunidade, a mesma Corte decidiu que "a prescrição é causa extintiva da pretensão e não do direito abstrato de ação. Por isso é instituto de direito material, a ela se aplicando a lei do tempo em que teria ocorrido (RTJ 165/1020). Ambos os acórdãos foram reproduzidos a partir de Yussef Said Cahali que, por sua vez, explica: “O remédio jurídico origina-se das leis processuais, representando o caminho a ser percorrido por aquele que vai a juízo, dizendo-se com direito subjetivo, pretensão e ação, ou somente com ação; realizado o direito objetivo sem relutância, não terá sido necessário que o titular do direito subjetivo, da pretensão e ação, se socorresse do remédio jurídico processual (...) Em outros termos, o direito subjetivo, a pretensão e a ação preexistem ao exercício, ao uso dos remédios processuais. Daí resulta que a prescrição e a decadência integram o direito material (...)" (CAHALI, Yussef Said. Prescrição e decadência. São Paulo: Revista dos Tribunais, 2008, p.16-17). Em certa medida, o texto doutrinário mais influente em direito nacional a respeito do tema não esclarece suficientemente o caráter material da prescrição, ao tratar como critério de distinção entre a prescrição e a decadência as ações, aparentemente em sentido processual, segundo a classificação trinária (açõs constitutivas, declaratórias e condenatórias) (AMORIM FILHO, Agnelo. Critério científico para distinguir a prescrição da decadência e para identificar as ações imprescritíveis. Revista dos Tribunais. a.86, v.744, out.1997, p.725-750). 


\section{ANÁlise CRÍTICA DA DISCIPLINA DA PRESCRIÇÃo NO CÓDIGO CIVIL BRASILEIRO DE 2002}

Tal como antes afirmado, desconhece-se uma codificação isenta de críticas quanto ao tratamento do tema da prescrição. Com o Código Civil Brasileiro não poderia ser diferente.

As reservas ao trabalho do legislador, no entanto, devem ser justificadas, seja pela coerência científica, seja pela repercussão social de suas opções.

O Código Civil brasileiro acertou ao se aproximar do modelo alemão, estipulando que o objeto da prescrição seria a pretensão. Não parece atender aos pressupostos mínimos de rigorosidade científica, nem o modelo francês nem, tampouco, o modelo italiano.

O Código Civil Francês, ao unir sob o manto do instituto da prescrição também a aquisição mediante usucapião incorreu em erro, cujas origens remontam ao trabalho dos glosadores do século XII sobre as fontes romanas ${ }^{20}$.

${ }^{20}$ Estudos de Direito Romano apontam a inexistência de uma concepção unificada de prescrição ou, ainda, de um prazo para o exercício das ações. Ao contrário, as ações do ius civile seriam perpétuas (actiones perpetuae). Segundo Mario Amelotti, a busca por segurança e certeza nas relações jurídicas, por muito tempo, não se apresentou à cultura romana como um problema, tornando desnecessário uma orientação unificada sobre o assunto até o período pós-classico. No período das legis actiones, a orientação era pela perpetuidade. No período formulário, já se verificariam algumas figuras concernentes à eficácia extintiva do tempo, sem que seja possível, no entanto, unificálas em um conceito (AMELOTI, Mario. La prescrizione delle azioni in Diritto Romano. Milano: Giuffrè, 1958, p.1-23). Apenas no período pós-clássico, com Teodósio II, por volta do ano 424 D.C., cria-se um prazo geral para o exercício das ações e, com Justiniano, o meio de defesa do possuidor de opor uma exceção pela prescrição da ação reivindicatória (a chamada longi temporis praescriptio) foi considerada uma espécie de usucapião (Cf. VOCI, Pasquale. Istituzioni di Diritto Romano. 3.ed. Milano: Giuffrè, 1954, p.197 e p. 232; JÖRS, Paul; KUNKEL; Wolfgang. Derecho privado romano. Madrid: Labor, 1937, p. 191; KASER, Max. Direito privado romano. Lisboa: Calouste Gulbekian, 1999, p.59 e p.155). Daí a se considerar a prescrição como gênero que albergaria uma prescrição aquisitiva e outra extintiva, há muita diferença. Savigny explica a tentativa de se ampliar a noção de prescrição para a perda e a aquisição de direito, de modo a albergar também a usucapião: "Le principe de la phraseologie vicieuse que je combats se trouve déjà chez les glossateurs du douzième siècle, d'où il a passé dans le droit canon; mais là on se borne à représenter l'usucapion et la prescription des actions comme deux espéces d'un même genre" (SAVIGNY. Traité de Droit Romain. 2.ed. t.4. trad. M. Ch. Guenoux. Paris: Librairie de Firmin Didot Frères, 1856, p. 317 e 319). Nesse mesmo sentido, Massimo Corsale apresenta uma glosa de Cardinalis que demonstraria o caminho para a união de institutos tão diferentes: “venendo ora ai requisiti necessari per l'utile decorso del termine di prescrizione, occore rilevare come, specialmente dai canonisti, fosse richiesto nel Medievo il 'possesso'. É interessante a questo proposito ricordare una glossa del Cardinalis al c.45, C.XV, q.1 (7): 'Quod enim quis possidet, praescritione acquirit vel retinet, actionem enim (autem?) alterius, quam nullus possidet, praescribit nemo, sed contra actionem libertatem, quam sine interpellatione quis possidet, ipsam praescribit. Unde dicitur spatio XXX vel XL annorum omnis actio tollitur, etc...'. Le affermazioni contenute in questo brano si basano, su una concezione estremamente ampia del quasi-possesso utilizzata per assimilare la prescrizione estintiva alla acquisitiva, mediante la fusione in un unico istituto con gli stessi fondamenti" (CORSALE, Massimo. Verb. Prescrizione estintiva. Storia del diritto. In: Novissimo Digesto Italiano. t. XIII, p.641). No Brasil, o percurso e a crítica da união entre a usucapião e a prescrição são apresentados por PONTES DE MIRANDA. Tratado de Direito Privado. t. VI. Rio de Janeiro: Borsoi, 1955, p.98 e seguintes). 
Para além do equívoco na interpretação do Direito Romano - usualmente adotado como discurso competente para justificar soluções modernas ao direito privado ${ }^{21}$-, a opção de unir a usucapião à prescrição mostra insuficiências no plano teórico e prático.

Os elementos que integram o suporte fático da usucapião são completamente diferentes dos elementos que compõem o suporte fático da prescrição, sobretudo ante a crescente pluralidade de diferentes meios para se adquirir a propriedade mediante usucapião ${ }^{22}$; a eficácia do que se compreende por prescrição e usucapião é diametralmente oposta; a função prático-social da prescrição é completamente diversa da função práticosocial da usucapião. As causas que impedem, suspendem e interrompem a prescrição são, em geral, imprestáveis para a usucapião, até mesmo pela diferente função práticosocial de cada uma delas; a prescrição tem aplicação em todas as searas do direito civil e a usucapião é restrita ao direito das coisas.

Diante de tantas diferenças, qual o porquê de se unir estas duas figuras sob o manto do mesmo instituto, senão o apego a uma leitura equivocada das fontes romanas? O transcurso do tempo, verificável tanto na prescrição como na usucapião, não parece ser razão suficiente para uní-las em um mesmo instituto ${ }^{23}$.

O Código Civil Brasileiro também mostrou acerto ao se afastar do modelo italiano. A ideia de que a prescrição extingue um direito não se mostra coerente com a orientação normativa, já assentada em direito nacional, de que o pagamento de uma dívida prescrita pelo devedor não configuraria um pagamento indevido ou uma situação de enriquecimento sem causa (art. 882, CCB).

A dívida prescrita é tão existente como o crédito que lhe é correspectivo, ainda que seja mutilada de qualquer pretensão. Essa precisão conceitual se mostra importante ao se analisar a prescrição sob o aspecto funcional: ao versar sobre a prescrição nunca se teve em mente, pura e simplesmente, criar um impedimento para o credor receber aquilo que lhe é devido. Ainda que porventura isto venha a ocorrer, esta não é a função da prescrição ${ }^{24}$.

Outra evolução digna de nota foi a tentativa de separação dos prazos prescricionais exclusivamente nos artigos 205 e 206 do Código Civil, indicando-se que todos os demais

${ }^{21}$ A respeito do assunto, dentre outras obras do mesmo autor, cf. FONSECA, Ricardo Marcelo. Introdução teórica à história do direito. Curitiba: Juruá, 2010, p.23.

${ }^{22}$ Uma leitura da Constituição Federal Brasileira (arts.183 e 191), do Código Civil (arts.1238, 1239, 1240, 1242e 1260) e do Estatuto da Cidade, Lei n. ${ }^{0}$ 10.257/2001 (art. 9) esclarece as várias espécies de usucapião que atualmente são verificáveis em direito brasileiro.

${ }^{23}$ Sobre o assunto, cf. NEQUETE, Lenine. Prescrição aquisitiva e prescrição extintiva: semelhanças e diferenças. Ajuris. v.32, n.100, p.9-16.

${ }^{24}$ A função da prescrição diz respeito à "segurança e à paz públicas, para limite temporal à eficácia das pretensões e das ações. A perda ou destruição das provas exporia os que desde muito se sentem seguros, em paz, e confiantes no mundo jurídico, a verem levantarem-se - contra o seu direito, ou contra o que têm por seu direito pretensões ou ações ignoradas ou tidas por ilevantáveis. O fundamento da prescrição é proteger o que não é devedor e pode não mais ter prova da inexistência da dívida; e não proteger o que era devedor e confiou na inexistência da dívida, tal como juridicamente ela aparecia" (PONTES DE MIRANDA. Tratado de direito privado, t. VI. Rio de Janeiro: Borsoi, 1955, p.100). 
prazos ditos "extintivos", dispersos noutros setores da parte geral e da parte especial do código, seriam de natureza decadencial. O esforço do legislador rende frutos de operacionalidade, superando o Código revogado que foi marcado por uma extrema dificuldade de distinção entre os prazos prescricionais e decadenciais ${ }^{25}$.

A legislação brasileira, no entanto, no afã de conceituar a prescrição, abriu as portas de outras incoerências e insuficiências, teóricas e práticas. As principais críticas podem ser organizadas em sete pontos.

Em primeiro lugar, ao atribuir à prescrição uma eficácia extintiva da pretensão (peremptoriamente extintiva), o legislador incorreu em grave erro lógico ${ }^{26}$.

Tradicionalmente se concebe a possibilidade, em favor daquele que é beneficiado pela prescrição, de renunciar ao efeito da prescrição. O artigo 191 do Código Civil Brasileiro, nesse sentido, é expresso ao estabelecer que "a renúncia da prescrição pode ser expressa ou tácita, e só valerá (sic.), sendo feita, sem prejuízo de terceiro, depois que a prescrição se consumar (...)".

Se a prescrição extinguisse realmente a pretensão, fulminando-a em moldes peremptórios, a renúncia seria um ato jurídico capaz de conferir uma ressurreição daquilo que já foi extinto. Isso parece incoerente e sem sentido.

Já há muito tempo alguns juristas brasileiros advertiram que, conforme os contornos que a matéria tomou em direito nacional, a prescrição encobriria, paralisaria a pretensão, sem destruí-la (TOMASETTI (et alli), 1991, p.5; BERNARDES DE MELLO, 2008). Desse modo, aquele que se beneficiasse da eficácia limitadora prescricional poderia renunciar a tal eficácia para, deste modo, descobrir a pretensão.

Da equívoca afirmação de uma peremptória extinção da pretensão ${ }^{27}$, decorre um embaraço à compreensão de que a prescrição seria não uma causa extintiva, peremptória em sua aplicação, mas uma exceção substancial a ser oposta pelo interessado.

${ }^{25}$ Há limitações, no entanto, ante as situações que ensejam, por exemplo, alternativamente, pretensões e direitos potestativos (poderes formativos), como nos vícios redibitórios que conferem ao prejudicado pretensão ao abatimento do preço, sujeita ao prazo prescricional, e poder de rescisão do contrato, sujeito ao prazo de natureza decadencial. Neste sentido, cf. NERY JR, Nelson; NERY; Rosa Maria de Andrade. Código civil comentado. São Paulo: RT, 2008, p. 527. A respeito desta orientação no Código Civil brasileiro, cf. REALE, Miguel. História do novo código civil. São Paulo: Revista dos Tribunais, 2005, p.61.

${ }^{26}$ Em sentido contrário, defendendo a extinção ipso iure mediante prescrição, ainda que sob a dependência de alegação da parte interessada, cf. CABRAL DE MONCADA, Luís. Lições de Direito Civil. 4.ed. Coimbra: Almedina, 1995, p.734.

${ }^{27}$ Cite-se, dentre outros, a crítica de Enneccerus e Nipperdey: “(...) con el fin de salvaguardar la seguridad general del derecho y en orden a proteger contra las pretensiones ilegítimas, el ordenamiento jurídico tiene que aceptar también que él deudor poco escrupuloso, que sabe exactamente que él debe todavía, esté favorecido por las reglas de la prescripción. Pero sería poco decoroso el protegerle ipso iure. El deudor podrá invocar la prescripción, pero tendrá que echar sobre sí la legítima censura de conducirse con poco miramiento" (ENNECCERUSNIPPERDEY. Parte General. t.I. v.2. In: Enneccerus-Kipp-Wolff. Tratado de Derecho Civil. Barcelona: Bosch, 1981, p.1017-1018). 
É interessante notar que a expressão praescriptio surge desvinculada de qualquer ideia de aquisição ou perda de direitos, tomando contornos de exceção ${ }^{28}$, ou seja, de oposição a determinado efeito pretendido por outrem.

Mais que conceitual e teórica, esta orientação foi e continua sendo eminentemente prática, não se verificando qualquer razão para alterá-la.

A prescrição seria uma exceção porque sem a efetiva oposição do devedor à pretensão nada ocorreria automaticamente ao direito, à pretensão ou à ação do credor. $\mathrm{O}$ poder de se opor, mediante alegação da prescrição, necessariamente haveria de ser exercido pelo devedor para que fosse possível promover uma alteração no plano do direito material ${ }^{29}$.

Com isso, fica mais fácil compreender a possibilidade de renúncia à prescrição e, até mesmo, a função do instituto que, como antes explicado, nunca se destinou a impedir que alguém recebesse alguma prestação que é devida.

Se a prescrição extingue a pretensão, tal como está escrito no art. 189 do Código Civil Brasileiro, sob a perspectiva do direito positivo, a configuração do instituto como uma das espécies de exceções substanciais restaria prejudicada.

Talvez justamente em razão desse grave equívoco, o legislador brasileiro sentiuse à vontade para cometer um subsequente lapso muito pior: a determinação de que a prescrição pode ser conhecida de ofício, pelo magistrado, tal como prevê a Lei n. ${ }^{\circ}$ $11.280 / 2006$, especialmente quanto ao $\S 5^{\circ}$ do art. 219 do CPC.

Não se sabe se o raciocínio foi o de que, uma vez definitivamente extinta a pretensão pelo advento da prescrição, não haveria razão para não conferir ao Juiz o poder de reconhecer este fato de uma vez, agregando a aparente vantagem de desobstruir as pautas do Poder Judiciário de maneira célere.

28 "Praescriptio est exceptio ex tempore substantiam capiens quae actioni personali vel in rem opponitur" (BALBI, G.F. Tractatus praescriptionum. Veneza, 1574, n.2, cart. 5 Apud CORSALE, Massimo. Verb. Prescrizione estintiva. Storia del diritto. In: Novissimo Digesto Italiano. t. XIII, p.641). Savigny, por sua sua vez, explica que "dans les sources du droit, le mot praescriptio ne signifie jamais acquisition ou perte, toujours il a le sens d'exceptio, exception" (SAVIGNY. Traité de Droit Romain. 2.ed. t.4. trad. M. Ch. Guenoux. Paris: Librairie de Firmin Didot Frères, 1856, p. 317). Trata-se, portanto, de uma interessante situação em que o abandono da releitura moderna das fontes do direito romano representa um retrocesso. Conforme atentou Windscheid: "Secondo il diritto romano invero non s'estinguono in generale i diritti, ma bensì in generale le ragioni (azioni) per la continuazione del loro non uso (...) La prescrizione toglie di mezzo la ragione. Non che la estingua, la ragione continua a sussistere; ma la toglie di mezzo col produrre una eccezione, che la esclude" (WINDSCHEID, Bernardo. Diritto delle pandette. trad. Fadda \& Bensa. Torino: UTP, 1902, p.425 e 444, respectivamente). Sobre a progressiva construção da prescrição como exceção, cf. AMELOTI, La prescrizione delle azioni in Diritto Romano, p.13).

${ }^{29}$ Marcos Bernardes de Mello elucida:“A prescrição (...) não decorre da obrigação prescrita, mas é produto de um ato-fato (=inação do credor + decurso de tempo), que a gera em favor do devedor, oponível (=contra) ao credor. Trata-se, como se pode concluir, de um poder jurídico, que, por isso, se situa no plano das posições ativas e não passivas". Sobre a noção de exceção e, especificamente, da prescrição como exceção, cf. PONTES DE MIRANDA. Tratado de direito privado, t. VI. Rio de Janeiro: Borsoi, 1955, p.100. A respeito das exceções em direito material, cf. BOLAFFI, Renzo. Le eccezioni nel diritto sostanziale. Milano: Società Editrice Libraria, 1936, especialmente nas páginas 100 e seguintes. 
As consequências dessa alteração legislativa, no entanto, são desastrosas. Ao se atacar algumas das pilastras mais importantes que sustentam teoricamente a prescrição, criou-se um embaraço para a aplicação cotidiana do instituto e se afastou, absolutamente sem razão, o direito brasileiro das soluções encontradas em direito comparado sobre o mesmo tema.

Não se trata de um apego aos conceitos, frise-se bem. Ao conhecer de ofício uma prescrição, o Poder Judiciário pode induzir um comportamento de não pagamento pelo devedor que, uma vez acionado, poderia cumprir com a sua obrigação.

Ao conhecer de ofício uma prescrição, o juízo pode desconhecer circunstâncias de interrupção, de suspensão ou de impedimento do prazo prescricional, ou até mesmo de renúncia do credor à prescrição, forçando o autor a se servir de recursos processuais para que sua demanda possa ter prosseguimento.

Não bastasse tudo isso, o conhecimento de ofício da prescrição retira do credor o poder, fundado em legítimo exercício da autonomia privada, de renunciá-la.

Essa confusão somente pode ser superada com um grande esforço hermenêutico que já se apresenta na doutrina e jurisprudência, inclusive com entendimento do Superior Tribunal de Justiça que sugere a limitação da aplicação do dispositivo apenas após a oitiva da outra parte ${ }^{30}$.

Em segundo lugar, o Código Civil Brasileiro indica que a prescrição extinguiria a pretensão sem explicar o que seria a tal pretensão a ser fulminada ${ }^{31}$.

\footnotetext{
${ }^{30}$ Conforme anota Flavio Tartuce “(...) a autonomia privada manifestada pelo direito de se pagar uma dívida prescrita em juízo e renunciando à prescrição, estará seriamente ferida. Sendo a autonomia privada um valor associado à liberdade constitucional, pode-se até afirmar que a inovação é inconstitucional, caso este direito de renúncia à prescrição não seja assegurado" (TARTUCE, Flavio. Direito Civil: Lei de introdução e parte geral. 6.ed. São Paulo: Método, 2010, p.439). O mesmo autor menciona, por um lado, a súmula n. 409 do STJ que reforçaria o poder de conhecimento de ofício da prescrição na execução fiscal e, por outro lado, interessante precedente do Superior Tribunal de Justiça que sintetiza algumas das dificuldades acima apontadas para aplicação da regra processual em comento: “(...) Apesar da clareza da legislação processual, não julgamos adequado o indeferimento oficioso da inicial. De fato, constata-se uma perplexidade. O magistrado possui uma 'bola de cristal' para antever a inexistência de causas impeditivas, suspensivas ou interruptivas ao curso da prescrição?” (...) A prévia oitiva da Fazenda Pública é requisito para a decretação a prescrição (...) Deve-se interpretar sistematicamente a norma processual que autoriza o juiz decretar ex officio a prescrição e a existência de causas interruptivas e suspensivas do prazo que não podem ser identificadas pelo magistrado apenas à luz dos elementos constantes do processo" (STJ, Resp n. 1.005.209/RJ, Rel. Min. Castro Meira, $2^{\mathrm{a}}$ turma, j. 08.04.2008, DJ 22.04.2008). Sobre o assunto, conferir os ensaios publicados em revistas especializadas. CIANCI, Mirna. A prescrição na Lei 11.280/2006. Revista de Processo n. 148, p.31 e seguintes, 2007. Sobre a aplicação dessa regra no direito do trabalho, cf. GARCIA, Gustavo Filipe Barbosa Garcia. Prescrição de ofício: da crítica ao direito legislado à interpretação da norma jurídica em vigor. Revista de Processo, n.145, p.163 e seguintes, 2007; ALBUQUERQUE JÚNIOR, Roberto Paulino de. Reflexões iniciais sobre um profundo equívoco legislativo - ou de como o art. $3 .^{\circ}$ da Lei n. ${ }^{\circ} 11.280 / 2006$ subverteu de forma atécnica e desnecessária a estrutura da prescrição no direito brasileiro. Revista de Direito Privado, n.25, p.280, 2006

${ }^{31}$ A respeito da dificuldade em se definir a pretensão em direito brasileiro, cf. BARBOSA MOREIRA, José Carlos. Notas sobre pretensão e prescrição no sistema do novo Código Civil brasileiro. Revista Trimestral de Direito Civil. v.11, jul/set, 2002, p.67. Referida crítica foi também realizada por MALACHINI, Edson Ribas. Prescrição e decadência. V Ciclo Nacional de Estudos sobre Pontes de Miranda, 2007 (anotações do autor).
} 
Uma vez escolhida a árdua tarefa de conceituar a prescrição, o legislador parou na metade do caminho (ao contrário do próprio BGB e do recente Código Civil da Catalúnia $)^{32}$. Talvez não devesse se perder em definições e conceitos. A outra metade do caminho que se deixou para trás, no entanto, lamentavelmente, pode conduzir a grandes confusões ${ }^{3334}$.

Alguns autores já defendem que a pretensão seria equivalente à noção de $a c ̧ a ̃ o$ em sentido material ${ }^{35}$, o que não se pode aceitar ante a profunda diferença verificável

32 Ver notas de rodapé $\mathbf{n} .9$ e 10 .

33 A expressão "pretensão" não é familiar à maior parte da doutrina brasileira, nem o era à cultura jurídica alemã, sendo potencial criadora de muitas confusões teóricas. A experiência alemã pode antever dificuldades do direito brasileiro de tratar a prescrição da pretensão, tal como previsto no art. 189 do Código Civil, ainda que, neste particular, cremos que o direito positivo nacional se tornou mais técnico e preciso. A estipulação do termo pretensão como objeto da prescrição, no direito positivo alemão, foi verdadeiramente tormentosa nos debates que antecederam a edição do BGB. Conforme explicam Fadda e Bensa, a expressão Anspruchsverjährung (prescrição da pretensão), não seria usual à cultura jurídica alemã da época, sendo mais comum os termos Retchsverjährung (prescrição do direito), Shuldverjährung (prescrição do débito) e, mais que qualquer outra, Klagenverjährung (prescrição da ação). Para prevalecer a Anspruchsverjährung foi preciso que a tese de Windscheid prevalecesse sobre as três outras. Nas palavras desses autores: “(...) si soggiungeva, contro la prima di queste tre espressioni, che essa è inesatta in quanto il diritto reale non è tocco dalla prescrizione della ragione che ne deriva; contro la seconda, che Shuld significa normalmente l'obbligo derivante da un vincolo personale e ha il corrispondente in Forderung (credito); contro la terza, che dà campo all'equivoco di una prescrizione rivolto contro la persecuzione giudiziale, mentre l'oggetto della prescrizione è la facoltà che sta a base dell'azione (...) Il dibattito si ripetè in seno alla seconda Commissione, ma il concetto della Anspruchsverjährung trionfò anche qui, sebbene con gravi difficoltà, tanto che la proposta di porre l'intitolazione Klagenverjährung fu respinta a parità di voti (10 contro 10v. Protocolli, I, p.194 sgg.). In definitiva il §161 del II Prog. e il § 189 del proggetto presentato al Reichstag, come il § 194 del Codice accettano il concetto del W. in questa forma 'il diritto di esigere da altri un fatto od una ommissione (Anspruch) soggiace alla prescrizione'. Ed è con riluttanza, che i civilisti si assoggettano alla consacrazione legislativa della dottrina del W. (FADDA, Carlo; BENSA, Paolo Emilio. Note e riferimenti al diritto italiano vigente. In: WINDSCHEID, Bernardo. Diritto delle pandette. trad. Fadda \& Bensa. Torino: UTP, 1902, p.1078). Pontes de Miranda propõe a questão sobre "o que é pretensão?" no quinto volume do Tratado de Direito Privado. Podemos colher, a partir de trechos da obra de Pontes de Miranda, uma tentativa de definição de pretensão: "Pretensão é a posição subjetiva de poder exigir de outrem alguma prestação positiva ou negativa (...) Pretensão é, pois, a tensão para algum ato ou omissão dirigida a alguém. O pre- esta, aí, por 'diante de si (...). Na pretensão, o direito tende para diante de si, dirigindo-se para que alguém cumpra o dever jurídico (...). Atividade potencial para frente, faculdade jurídica de exigir; portanto, algo mais" (PONTES DE MIRANDA. Tratado de Direito Privado, v.V, p.452). Segundo Enneccerus e Nipperdey "a pretensão e o direito de exigir de outra pessoa um ato ou uma omissão. Este direito pode nascer do poder decorrente de um direito absoluto ou de um direito relativo. Distingue-se, pois, segundo seja a relação jurídica da qual procede a pretensão, entre pretensões obrigatórias, reais, de direito de família e sucessórias" (ENNECCERUS-NIPPERDEY. Derecho Civil (parte general). t.I. v.II $-2^{\mathrm{a}}$ parte. In: ENNECCERUS-KIPP-WOLFF. Tratado de derecho civil. Barcelona: Bosh, 1981, p.957).

${ }^{34}$ A confusão já se inicia pela dificuldade em se traduzir o termo alemão Anspruch. Sobre o assunto, Carlos Melon Infante apresenta interessante explicação ao traduzir o BGB para compor o apêndice do clássico Tratado de Direito Civil por Enneccerus, Kipp e Wolf em idioma espanhol: “Es la 'pretensión' una facultad derivada de un derecho subjetivo: la facultad de ejercitar el contenido del derecho de que ella misma es consecuencia. El equivalente de la 'Anspruch' en nuestro Derecho es la acción; la equivalencia no es, sin embargo, plena, puesto que nuestra acción tiee de la ‘Anspruch' alemana y de la 'Klage’ alemana (acción propriamente dicha)” (INFANTE, Carlos Melon. Código Civil Aleman. Barcelona: Bosch, 1994, p.38, nota de rodapé n. 155).

${ }^{35}$ Neste sentido, THEODORO JÚNIOR, Humberto. Comentários ao código civil. Rio de Janeiro: Forense, 2003, p.152. José Carlos Moreira Alves enuncia expressamente: "o projeto considera como pretensão o que 
entre cada uma dessas categorias eficaciais, com profundas consequências práticas (com esforço de síntese e simplificação, pode-se dizer que quem detém poder de exigir, segundo seus critérios, pode efetivamente agir ou não, empreendendo, deste modo, a ação em sentido material. Pretensão e ação, portanto, são categorias eficaciais flagrantemente diferentes) ${ }^{36}$.

Em terceiro lugar, mostra-se equivocada a afirmação de que "violado o direito, nasce para o titular a pretensão". A pretensão, como poder de exigir uma prestação de outrem, surge independentemente de qualquer violação ao direito que lhe é correspondente.

O exemplo do contrato de mútuo, antes apresentado, mais uma vez é elucidativo: o advento do termo para a devolução de uma importância mutuada não representa a violação do contrato ou do direito do credor mutuante ${ }^{37}$.

Ao se determinar o surgimento da pretensão apenas a partir da violação do direito, para além da imprecisão teórica denunciada, percebe-se uma restrição ideológica inaceitável.

Se a pretensão só surge com a violação do direito subjetivo, inexistiriam as pretensões inibitórias, destinadas a exigir uma prestação hábil a evitar a violação do direito e, até mesmo, a prática do ato ilícito por outrem.

As pretensões inibitórias são cada vez mais caras ao direito contemporâneo, mormente no que diz respeito à defesa dos direitos da personalidade que, ao fim e ao cabo, dificilmente são adequadamente tutelados por uma prestação patrimonial posterior ao dano ${ }^{38}$. A falta de técnica legislativa exige do intérprete um esforço especial contrário aos postulados de operacionalidade que informam o Código. ${ }^{39}$

Savigny denominava ação em sentido substancial ou material, em contraposição à ação em sentido formal ou processual" (MOREIRA ALVES, José Carlos. A parte geral do projeto de Código Civil brasileiro. São Paulo: Saraiva, 2003, p.188).

${ }^{36}$ Sobre o assunto, conferir, além de Pontes de Miranda e Marcos Bernardes de Mello, nas obras já citadas, vale conferir a didática explicação de BAPTISTA DA SILVA, Ovídio. Ação de imissão de posse. 2.ed. São Paulo: Revista dos Tribunais, 1997, p.35 e seguintes.

${ }^{37}$ Windscheid, mais uma vez, é esclarecedor: "Se invece la ragione personale intende ad un atto dell'obbligato, finchè quest'atto non si compia, la ragione non è soddisfatta, e quindi la prescrizione comincia, subito, senza che sia necessario lo avere richiesto dell'adempimento l'obbligato, nè che questi lo abbia ricusato" (WINDSCHEID, Bernardo. Diritto delle pandette. trad. Fadda \& Bensa. Torino: UTP, 1902, p.430). Em direito brasileiro, Marcos Bernardes de Mello explica: "Em verdade, a pretensão nasce no momento em que direito passa a ser exigível (no vencimento da obrigação, por exemplo), nunca quando é violado. Quem pode ser violada é a pretensão, porque contém exigibilidade, nascendo daí a ação (de direito material, como a pretensão)" (BERNARDES DE MELLO, Marcos. Teoria do fato jurídico: plano da validade. 8.ed. São Paulo: Saraiva, 2008, p.237, nota 372).

${ }^{38}$ A respeito do tema, seguimos MARINONI, Luiz Guilherme. Tutela inibitória. São Paulo: RT, 2003; ARENHART, Sérgio Cruz. Perfiz da tutela inibitória coletiva. São Paulo: RT, 2003.

${ }^{39}$ Nesse sentido, cite-se o enunciado n. 14 do CJF/STJ, proveniente da I Jornada de Direito Civil, que reconstrói art. 189 para superar suas insuficiências: “Art. 189: 1) o início do prazo prescricional ocorre com o surgimento da pretensão, que decorre da exigibilidade do direito subjetivo; 2) o art. 189 diz respeito a casos em que a pretensão nasce imediatamente após a violação do direito absoluto ou da obrigação de não fazer" 
Em quarto lugar, o Código Civil perdeu a oportunidade de estabelecer causas de impedimento ao curso prescricional em moldes mais abertos para determinadas situações de grave vulnerabilidade, e de difícil verificação do surgimento da pretensão e do polo passivo contra a qual ela se dirige.

A disciplina dos impedimentos ao curso da contagem do tempo na prescrição praticamente repetiu o Código Civil de 1916 e, ao assim proceder, perdeu uma importante oportunidade para concretizar as soluções pertinentes à diretriz da ética da situação propugnadas pelo coordenador do projeto do Código Civil.

Lembre-se, nesse sentido, a disciplina da matéria no Código de Defesa do Consumidor que, em casos de acidentes de consumo, fixa como ponto inicial para o lapso prescricional o efetivo conhecimento do dano e de sua autoria (art. 27 da Lei n. ${ }^{\circ}$ 8.078/90). Numa sociedade marcada por relações tão impessoais, os resquícios do discurso sobre o direito romano na chamada teoria da actio nata precisariam encontrar válvulas de alteração conforme as situações dos envolvidos.

Em quinto lugar, o Código Civil de 2002 trata, pelo menos explicitamente, apenas de pretensões obrigacionais. Isso pode conduzir a uma equívoca interpretação de que a prescrição atinge apenas as pretensões pertinentes ao direito das obrigações, relegando as pretensões de direito das coisas, de direito societário, e outros. A situação se torna mais perigosa, ainda, pela indistinção entre pretensões pessoais e pretensões reais que, mesmo com outra denominação, encontrava-se presente no Código Civil de 1916, com uma consolidada aplicação jurisprudencial (art.177, CCB 1916) ${ }^{40}$.

A sexta crítica se apresenta sobre a genérica determinação que a exceção prescreve no mesmo prazo da prescrição (Art. 190 do CCB). Conforme Windscheid, as exceções, em geral, não poderiam ser expostas à prescrição, uma vez que o titular desta posição ativa não poderia dela se servir quando melhor lhe conviesse ${ }^{41}$.

${ }^{40}$ As pretensões reais dirigem-se como os direitos de que emanam, contra todos. Há-as no direito das coisas, no direito de família e no direito das sucessões. Tem-se dito que as pretensões reais não exsurgem com o direito mesmo: é preciso que se dê conduta de alguém, contrária ao conteúdo do direito real ou do direito de família; portanto, sem violação não haveria pretensão real. Mas essa proposição confunde ação e pretensão: a pretensão preexiste, aí, à ação; aí, não é a pretensão que nasce mais tarde que o direito, é a ação (...) Porque direito e pretensão são diferentes, têm de ser diferentemente tratados: direito não prescreve; prescreve a pretensão ou a ação; a prescrição das pretensões reais somente começa do momento em que deixa de ser satisfeita; é contínua e negativa, de modo que não infringi-la é i-la satisfazendo continuamente; contra as pretensões de propriedade pode, às vezes, ser oposta exceção (direito de retenção), ainda que o direito do proprietário nada possa sofrer; a pretensão depende do direito, que lhe é base, com ele nasce, ou dele nasce, e com ele se extingue (ainda se foi cedida) (PONTES DE MIRANDA. Tratado das ações. t.I. São Paulo: Revista dos Tribunais, 1970, p.56-57).

41 "Le eccezioni, come tali, per la natura delle cose non sono sottoposte alla prescrizione, poichè il titolare non può farle valere quando vuole, ma a tal fine deve attendere, che si eserciti la ragione" (WINDSCHEID, Bernardo. Diritto delle pandette. trad. Fadda \& Bensa. Torino: UTP, 1902, p.448). 
A oposição da exceção, pelo menos em sua razão de ser, depende do prévio exercício de um direito, pretensão ou ação. A exceção visaria justamente impedir que os efeitos decorrentes de um direito, pretensão ou ação tenham repercussão ${ }^{42}$.

Se é assim, não faz o menor sentido a determinação legal pura e simples, tal como lançada no art. 190 de que "A exceção prescreve no mesmo prazo em que a pretensão", até mesmo porque o poder de exceção não tem coincidência temporal como o surgimento da pretensão. Em princípio, a exceção, como defesa, só poderia ser manejada ante um exercício de uma pretensão (ação).

Mais uma vez, esforços hermenêuticos são necessários para tornar possível a aplicação da regra que, em si mesma, traz uma contradição. Segundo orientação doutrinária que procura adaptar o dispositivo, apenas as chamadas exceções dependentes seriam paralisadas pela prescrição ${ }^{43}$.

Em sétimo e último lugar, o Código Civil não apresentou qualquer orientação sobre a imprescritibilidade. Ainda que esta seja uma situação excepcional, a falta de um tratamento unificado (tal como se espera de um Código) deixa ao intérprete a difícil tarefa de garimpar as situações de imprescritibilidade ${ }^{44}$.

42 “A exceção, em direito material, contrapõe-se à eficácia do direito, da pretensão, ou da ação, ou de outra exceção" (PONTES DE MIRANDA, Tratado de Direito Privado. t. VI., p.5).

43 Segundo Moreira Alves: “essa norma não diz respeito às exceções substanciais autônomas, ou seja, àquelas que existem por si mesmas e não visam, em consequência, a fazer valer uma pretensão, mas, sim, a garantir uma certa posição jurídica contra o ataque injusto de outrem. O artigo 190 só se aplica quando da mesma relação jurídica depende esta, por ser a exceção o exercício da pretensão a título de defesa". Para justificar esse posicionamento, Moreira Alves recorre a Savigny: “É o que ocorre, por exemplo, com referência à exceção de contrato não cumprido, na hipótese assim figurada por SAVIGNY (Sistema del Diritto Romano Attuale, vol. V, trad. SCIALOJA, parágrafo 254, p.476, Torino, 1983): 'No ano de 1841 foi vendido um imóvel, devendo a tradição ocorrer de imediato, mas o pagamento do preço da compra deveria fazer-se no ano de 1843; por ambas as partes foi negligenciada a execução. A actio empti prescreve no ano de 1871, a actio venditi no ano de 1873 (porque só poderia ter sido ela intentada no ano de 1843). Durante todo esse tempo cada uma das partes tinha a exceptio non impleti contractus, se o adversário quisesse agir. Se a actio venditi é intentada no ano de 1872, pergunta-se se o comprador, cuja ação já está prescrita há um ano, pode, ainda, valer-se da referida exceção'. Neste caso, tratandose de exceção dependente da pretensão, a resposta, em face do art. 190 do Projeto, será negativa, porque a exceção prescreveu quando ficou prescrita a pretensão. Em face dessa explicação, vê-se, claramente, que o dispositivo em causa não é aplicável à hipótese de não-repetição do que se pagou para solver dívida prescrita. Nesta, a exceção é autônoma, pois não depende da pretensão de cobrar o débito não pago, e, sim, resulta do pagamento espontâneo do devedor, apesar de já prescrita a pretensão do seu credor. As exceções autônomas continuam imprescritíveis, até porque não traduzem inércia de quem as pode invocar. Já as exceções dependentes de pretensões prescrevem com estas" (MOREIRA ALVES, José Carlos. A parte geral do projeto de Código Civil brasileiro. São Paulo: Saraiva, 2003, p.188)

${ }^{44}$ Sobre as hipóteses de imprescritibilidade no Código Civil, Humberto Theodoro Jr. apresenta o seguinte rol: a) a pretensão a partilha da herança (art. 2.013); b) a pretensão a dividir a coisa comum (art. 1.320); c) a pretensão à demarcação de imóveis limítrofes (art. 1.297); d) a pretensão à meação sobre os muros divisórios (art. 1.297, parágrafo primeiro); e) os direitos que não se traduzem em pretensões; f) as pretensões decorrentes dos direitos da personalidade; g) as pretensões surgidas em virtude dos direitos de estado e, em geral, os direitos derivados das relações de família. Humberto Theodoro Júnior, ainda, cita a tese de Manuel Albaladejo (La prescripcíon de la acción reinvindicatoria) que sustenta a possibilidade da prescrição da pretensão reivindicatória, como algo diverso da usucapião (THEODORO JÚNIOR, Humberto. Comentários ao código civil. Rio de Janeiro: Forense, 2003, p.166). 
Tal falha, ademais, contraria o princípio da operacionalidade que se procurou impingir na recente codificação. As pretensões fundadas nos direitos da personalidade e as pretensões para proteção dos estados pessoais são imprescritíveis, mediante interpretação, sem se esclarecer se a imprescritibilidade atingir o poder de exigir prestações de respeito aos direitos da personalidade ou, ainda, se atingiriam o poder de exigir indenização pelos danos decorrentes da violação.

Entre avanços e retrocessos, o Código Civil Brasileiro, à luz de uma investigação crítica, expõe a fragilidade das esperanças em se resolverem todos os problemas de um determinado instituto secular por meio de alterações legislativas.

Mais do que nunca, diante de um Código recente, o papel do intérprete é insuperável e, em tema de prescrição, tal como se procurou demonstrar, continua presente e urgente.

\section{REFERÊNCIAS}

ALBUQUERQUE JÚNIOR, Roberto Paulino de. Reflexões iniciais sobre um profundo equívoco legislativo - ou de como o art. $3 .^{\circ}$ da Lei n. ${ }^{\circ}$ 11.280/2006 subverteu de forma atécnica e desnecessária a estrutura da prescrição no direito brasileiro. Revista de Direito Privado, n.25, p.280, 2006.

AMELOTI, Mario. La prescrizione delle azioni in Diritto Romano. Milano: Giuffrè, 1958.

AMORIM FILHO, Agnelo. Critério científico para distinguir a prescrição da decadência e para identificar as ações imprescritíveis. Revista dos Tribunais. a.86, v.744, out.1997, p.725-750.

ANDRADE, Manuel A. D. Teoria geral da relação jurídica. t.II. Coimbra: Almedina, 1988.

ARENHART, Sérgio Cruz. Perfiz da tutela inibitória coletiva. São Paulo: RT, 2003.

BAPTISTA DA SILVA, Ovídio. Ação de imissão de posse. 2.ed. São Paulo: Revista dos Tribunais, 1997.

BARBOSA MOREIRA, José Carlos. Notas sobre pretensão e prescrição no sistema do novo Código Civil brasileiro. Revista Trimestral de Direito Civil. v.11, jul/set, 2002.

BERNARDES DE MELLO, Marcos. Teoria do fato jurídico: plano da eficácia. 3.ed. São Paulo: Saraiva, 2007.

BERNARDES DE MELLO, Marcos. Teoria do fato jurídico: plano da existência. 15.ed. São Paulo: Saraiva, 2008.

BERNARDES DE MELLO, Marcos. Teoria do fato jurídico: plano da validade. 8.ed. São Paulo: Saraiva, 2008.

BOLAFFI, Renzo. Le eccezioni nel diritto sostanziale. Milano: Società Editrice Libraria, 1936.

CABRAL DE MONCADA, Luís. Lições de Direito Civil. 4.ed. Coimbra: Almedina, 1995, p.740.

CAHALI, Yussef Said. Prescrição e decadência. São Paulo: Revista dos Tribunais, 2008.

CIANCI, Mirna. A prescrição na Lei 11.280/2006. Revista de Processo n. 148, p.31 e seguintes, 2007.

CORSALE, Massimo. Verb. Prescrizione estintiva. Storia del diritto. In: Novissimo Digesto Italiano. t. XIII. 
EHRHARDT JR, Marcos. Direito Civil: LICC e Parte Geral. v.I. Salvador: JusPodivm, 2009.

ENNECCERUS-NIPPERDEY. Parte General. t.I. v.2. In: Enneccerus-Kipp-Wolff. Tratado de Derecho Civil. Barcelona: Bosch, 1981.

FADDA, Carlo; BENSA, Paolo Emilio. Note e riferimenti al diritto italiano vigente. In: WINDSCHEID, Bernardo. Diritto delle pandette. trad. Fadda \& Bensa. Torino: UTP, 1902.

FERREIRA, Daniel Brantes. Teoria dos direitos subjetivos. Rio de Janeiro: GZ, 2009.

FONSECA, Ricardo Marcelo. Introdução teórica à história do direito. Curitiba: Juruá, 2010.

FRADERA, Véra Maria Jacob. Reflexões sobre a contribuição do direito comparado para a elaboração do direito comunitário. Belo Horizonte: Del Rey, 2010, em especial p.158 e seguintes.

GARCIA, Gustavo Filipe Barbosa Garcia. Prescrição de ofício: da crítica ao direito legislado à interpretação da norma jurídica em vigor. Revista de Processo, n.145, p.163 e seguintes, 2007.

HOHFELD, Wesley Newcomb. Fundamental legal conceptions as applied in judicial reasoning. New Haven: Yale University Press, 1920.

INFANTE, Carlos Melon. Código Civil Aleman. Barcelona: Bosch, 1994.

JÖRS, Paul; KUNKEL; Wolfgang. Derecho privado romano. Madrid: Labor, 1937.

KASER, Max. Direito privado romano. Lisboa: Calouste Gulbekian, 1999.

MALACHINI, Edson Ribas. Prescrição e decadência. V Ciclo Nacional de Estudos sobre Pontes de Miranda, 2007 (anotações do autor).

MARINONI, Luiz Guilherme. Tutela inibitória. São Paulo: RT, 2003.

MESSINEO, Francesco. Manuale di Diritto Civile e Commerciale. Milano: Giuffrè, 1957.

MOREIRA ALVES, José Carlos. A parte geral do projeto de Código Civil Brasileiro. 2.ed. São Paulo: Saraiva, 2003.

MOTA PINTO, Carlos Alberto. Teoria geral do Direito Civil. 3.ed. Coimbra: Almedina, 1993.

NEQUETE, Lenine. Prescrição aquisitiva e prescrição extintiva: semelhanças e diferenças. Ajuris. v. 32, n. 100

NERY JR, Nelson; NERY; Rosa Maria de Andrade. Código civil comentado. São Paulo: RT, 2008.

NOGUEIRA, Pedro Henrique Pedrosa. Teoria da ação de direito material. Salvador: Juspodivm, 2008.

PONTES DE MIRANDA. Tratado das ações. t.I. São Paulo: Revista dos Tribunais, 1970.

PONTES DE MIRANDA. Tratado de Direito Privado. t. VI. Rio de Janeiro: Borsoi, 1955.

PONTES DE MIRANDA. Tratado de Direito Privado. t.I. 3.ed. Rio de Janeiro: Borsoi, 1970.

PRATA, Ana. Dicionário jurídico. t.I. 5.ed. Coimbra: Almedina, 2008.

REALE, Miguel. História do novo código civil. São Paulo: Revista dos Tribunais, 2005.

SAVIGNY. Traité de Droit Romain. 2.ed. t.4. trad. M. Ch. Guenoux. Paris: Librairie de Firmin Didot Frères, 1856.

TARTUCE, Flavio. Direito Civil: Lei de introdução e parte geral. 6.ed. São Paulo: Método, 2010. 
THEODORO JÚNIOR, Humberto. Comentários ao código civil. Rio de Janeiro: Forense, 2003.

TOMASETTI, Alcides et. alli. Comentários à Lei de locações de imóveis urbanos. São Paulo: Saraiva, 1991.

VASCOnCELOS, Pedro Pais de. Teoria geral do direito civil. 3.ed. Coimbra: Almedina, 2005.

VOCI, Pasquale. Istituzioni di Diritto Romano. 3.ed. Milano: Giuffrè, 1954.

WINDSCHEID, Bernardo. Diritto delle pandette. trad. Fadda \& Bensa. Torino: UTP, 1902.

Recebido: novembro 2010 Aprovado: abril 2010 